\title{
Back to Engel? Some evidence for the hierarchy of needs
}

\author{
Andreas Chai · Alessio Moneta
}

(C) Springer-Verlag 2012

\begin{abstract}
Using UK household expenditure data spanning over four decades (1960-2000), this paper employs Engel's needs-based approach to analyzing household expenditure patterns and finds evidence for the existence of a stable hierarchy of expenditure patterns at low levels of household income. Second, we investigate how rising household income influences the manner in which total expenditure is distributed across Engel's expenditure categories. Our results suggest that i) total household expenditure is distributed across Engel's expenditure categories in an increasingly even manner as household income increases and ii) over time, there has been an acceleration in the rate at which household expenditure patterns become diversified as household income rises. Finally, we consider how the shape of Engel Curves may help shed light on the relationship between goods and the underlying needs they serve.
\end{abstract}

Keywords Hierarchy of needs • Engel curves • Engel's law

JEL Classification $\mathrm{B} 23 \cdot \mathrm{B} 25 \cdot \mathrm{C} 14 \cdot \mathrm{D} 12$

A. Chai $(\bowtie)$

Griffith Business School, Gold Coast Campus, Griffith University, Gold Coast, Qld, 4222, Australia

e-mail: a.chai@griffith.edu.au

\section{A. Moneta}

Max Planck Institute of Economics, Evolutionary Economics Group,

Jena, Germany

e-mail: moneta@econ.mpg.de

\section{A. Moneta}

Laboratory of Economics and Management, Scuola Superiore Sant'Anna, Piazza Martiri della Libertà, 33, 56127 Pisa, Italy 


\section{Introduction}

The set of needs that motivate consumption activity is an important theoretical concept which has a long tradition in economic thought (see inter alia Menger 1871; Marshall 1890; Georgescu-Roegen 1954). Many scholars posit that some of these needs are related to the biologically-evolved nature of homo sapiens (e.g. Witt 2001). Moreover, the fact that some of these needs are subject to satiation can provide important behavioral micro foundations for models in which changes in the industrial composition of growing economies are linked to compositional changes in household expenditure patterns (see inter alia Aoki and Yoshikawa 2002; Metcalfe et al. 2006; Saviotti and Pyka 2008). Beyond models of structural change, the existence of a universally-shared set of needs has fundamental implications for the analysis of household expenditure patterns.

In this regard, it is a little known fact that Ernst Engel devised a classification method to measure how different needs affect household spending patterns. In particular, he found empirical regularities among the expenditure patterns of low income households which he claims to support the existence of a hierarchy amongst needs (Engel 1857). Using UK household expenditure data spanning four decades (1960-2000), we examine whether the distribution of consumption expenditure across Engel's expenditure categories at the lowest income levels is stable and reflects the same order found by Engel. This is done by employing Engel's classification system by which goods are classified according to the needs they serve. It would seem unlikely this conjecture would be confirmed in light of the major changes in the number and variety of goods available to households, as well as the growth of real household income levels that has taken place since Engel's era. Nevertheless, we find evidence that the order Engel inferred to exist in the spending patterns of low income households in 1857 is still present in the expenditure patterns of low income households of today.

Second, we examine how rising household income leads to changes in the manner in which total expenditure is distributed across expenditure categories. This is done by measuring how evenly total expenditure is distributed across Engel's expenditure categories at high and low household income levels using the Gini measure of inequality. Here, our results suggest that total household expenditure is distributed across Engel's expenditure categories in an increasingly even manner as household income increases. In other words, as households become rich, they diversify their spending patterns. There appears to exist a tendency for this diversification to take place in a way that the differences between the budget shares dedicated to different needs fall as income increases. This new 'addendum' to Engel's Law has implications for understanding demand-driven structural change. Moreover, when examining the way in which household diversification patterns change over time, we find evidence that there has been an acceleration in the rate at which household expenditure patterns become diversified as household income rises. Whilst a stable hierarchy of expenditure patterns is present among low income households 
across all of the observed years, the rate at which this order breaks down with additional increases in household incomes appears to have accelerated in more recent years.

Finally, we discuss the shortcomings of Engel's classification method in which the link between goods and the needs they serve are made with little theoretical justification. An important question in this regard is whether it is possible to develop a way of empirically identifying the number of needs that goods are connected to particular expenditure categories. We explore such a possibility by building on a theoretical insight from the literature on lexicographic preferences about how the shape of the Engel Curve (EC) for a good may be affected by the range of needs to which the good is linked. Comparing the shapes of ECs, we find certain 'lower order' goods that directly serve needs possess relatively similar EC shapes relative to 'higher order' goods.

This paper is structured as follows. Section 2 briefly reviews Engel's results, while Section 3 discusses both the opportunities and pitfalls of pursuing Engel's evolutionary approach to analyzing household expenditure patterns. Section 4 examines whether modern household expenditure data supports Engel's claim of a hierarchy amongst needs. Section 5 examines the manner and pace at which the uncovered order breaks down as household income levels rise. Finally, Section 6 considers what the shape of Engel Curves may reveal about the relationship between the goods and the range of underlying needs they serve.

\section{Engel's hierarchy}

More than 150 years ago, Ernst Engel undertook one of the earliest attempts to study empirically the expenditure patterns of low incomes household in order to shed light on their living standards. Despite its well-known reputation, it is a little known fact that, in this study, Engel claims to have found evidence that the evolved biological nature of humans generate empirical regularities in the distribution of households expenditure at low income levels. This section briefly reviews Engel's results and discusses both the opportunities and pitfalls of pursuing his evolutionary approach to analyzing household consumption expenditure patterns in the context of the prevailing economic literature.

Writing some seventy years before income was systematically analyzed in economic theory (Stigler 1954:102), the theoretical starting point for Engel's inquiry was to analyze the Bedürfnisse (needs) which motivate consumption and how their influence changes as household income rises. A key facet of his work is to understand why a change in the income levels of households affects the composition of consumption expenditure and why preferences are not constant with rising income (in modern parlance, why preferences are nonhomothetic). While the use of the concept of needs in economic theorizing was certainly not unique to Engel (e.g. Menger 1871), what was unique was his 
empirical approach in analyzing the effects of needs and his argument that needs have their origins in human evolution. ${ }^{1}$ As Engel put it:

"All living things are born with a number of needs, whose non-satisfaction leads to death. The human being is not an exception. Also in him works the urge to satisfy (these needs) with a natural power that can overcome strong constraints that either carry humans away from or lead them to victory"(Engel 1895: 8). ${ }^{2}$

Engel proceeds by studying how household expenditure is distributed across needs rather than goods and services. Therefore, a real innovation in his work is that he developed a method for empirically measuring the impact that particular needs have on consumption patterns over a range of observed income. He does this by aggregating preexisting expenditure data on individual goods and services, found in Ducpétiaux (1855), into larger expenditure groups that are related to the satisfaction of particular needs. In doing so, Engel assumes that all individuals share the same set of needs at low income levels and possess the same potential for developing higher-order needs, such as education. Engel justifies this assumption on the basis of the aforementioned conjecture that needs have their origins in the evolved biological nature of humans. The list of needs includes the need for nourishment, clothing, accommodation, heating and light, household goods, intellectual education (which included some forms of entertainment), public safety, health and recreation and personal services (Engel 1857:6). Shown in Table 1, the resulting taxonomy of consumption expenditure was far more detailed relative to standard expenditure taxonomies of the time.

In terms of the way in which needs are linked to the consumption of goods, Engel makes a priori assumptions about the connection between goods and the underlying needs they serve. He assumes all households consume goods and services for the same purpose. For example, all households consume food specifically for the sake of nourishment. Thus, households possess a common understanding about the function that goods and services serve. Most goods and services are also assumed to have a single purposes in that they are linked to the satisfaction of a single need. Thus, expenditure on travel was grouped with recreational expenditure as Engel reasoned that both

\footnotetext{
${ }^{1}$ In the literature, Engel was thus perceived as a pioneer of an evolutionary approach to economics: "By his study on consumption alone Engel came to appreciate the modifiable nature of human beings. This is a central thought in modern economics which many students have only recently been coerced into accepting by the triumph of evolutionary philosophy" (A. G. Warner, Publications of the American Statistical Association, 1896).

"Niemand weiss, warum es so ist, aber es ist so, dass alles Lebende mit einer Reihe von bedürfnissen geboren wird, deren Nichtbefriedigung den Tod herbeiführt. Der Mensch macht hiervon am wenigsten eine Ausnahme. Auch in ihm wirkt der Drang der Befriedigung mit der Gewalt einer Narturkraft, dies selbst über starke Fesseln den Sieg davon trägt oder aber darin zu Grunde geht."
} 
Table 1 Engel's expenditure categories

\begin{tabular}{|c|c|}
\hline Needs (Bedürfnisse) & Relevant expenditures \\
\hline 1. Nourishment (Nahrung) & $\begin{array}{l}\text { Daily nourishment from meals and beverages, } \\
\text { spices, stimulants (e.g. alcohol, coffee), tobacco, } \\
\text { occasional dining out, etc. }\end{array}$ \\
\hline 2. Clothing (Kleidung) & $\begin{array}{l}\text { Clothing and shoes of all kinds; underwear, } \\
\text { jewelry and toiletries; clothing accessories }\end{array}$ \\
\hline 3. Housing (Wohnung) & $\begin{array}{l}\text { Shelter, furniture, household appliances; beds } \\
\text { and bedding; insurance for housing and furniture. }\end{array}$ \\
\hline 4. Heating and Lighting (Heizung) & $\begin{array}{l}\text { Wood, coal and gas heating; lighting via candles, } \\
\text { oil and gas }\end{array}$ \\
\hline 5. Tools for work (Geräthe) & $\begin{array}{l}\text { Tools, machines, mechanical instruments; } \\
\text { crockery and vessels etc.; all kinds of metal, } \\
\text { earths, stones, glass, porcelain, leather, pulp, } \\
\text { rubber etc.; wagons, boats, saddles and } \\
\text { equipment etc.; means of communications etc. }\end{array}$ \\
\hline 6. Intellectual education (Erziehung) & $\begin{array}{l}\text { Education, tuition; church; tools for education, } \\
\text { tuition and worship; scientific equipment, } \\
\text { literary and artistic production; intellectual } \\
\text { rejuvenation and educations, music, theater } \\
\text { etc.; musical instruments }\end{array}$ \\
\hline 7. Public safety (öffentliche Sicherheit) & $\begin{array}{l}\text { Legal protection; administration; police; state } \\
\text { defence; care for the poor etc. }\end{array}$ \\
\hline $\begin{array}{l}\text { 8. Health and recreation } \\
\text { (Gesundheitspflege) }\end{array}$ & $\begin{array}{l}\text { Medical treatment and pharmaceutical expenses, } \\
\text { bathing; outdoor recreation, play, recreational } \\
\text { travel.- Life insurance }\end{array}$ \\
\hline 9. Personal service (Dienstleistungen) & $\begin{array}{l}\text { Personal services attained from use of domestic } \\
\text { servants of all kinds }\end{array}$ \\
\hline
\end{tabular}

Source: Engel (1857: 5-6).

types of expenditure served the same need for health and recreation. No real theoretical justification was provided for why he thought these expenditure categories served the same underlying need.

In other cases, Engel assumes a priori that goods and services do have multiple purposes. He constructs two special categories for these, which he labels 'tools and means for work' as well as 'personal services'. Engel acknowledges that it is difficult to identify the needs that these particular goods and services satisfied (Engel 1857:7) and that this issue requires more attention, as such expenditures do not serve their specific needs but are incurred by consumers in the process of satisfying other needs. In this regard, Engel recognizes that there exists not only an order amongst needs, but also another type of order amongst goods: some goods directly satisfy the consumer's needs, while others are used by consumers to satisfy needs in a more indirect fashion. This will be discussed further in Section 5.

In contrast to existing expenditure aggregation methods, we argue that the approach pursued by Engel has some methodological advantages. Current approaches that are widely used in the modern literature on household 
Table 2 Budget shares of belgian workmen's families

\begin{tabular}{lccc}
\hline Needs & Family type & & \\
\cline { 2 - 4 } & On relief & $\begin{array}{l}\text { Poor but } \\
\text { independent }\end{array}$ & Comfortable \\
\hline Nourishment & 70.89 & 67.37 & 62.42 \\
Clothing & 11.74 & 13.16 & 14.03 \\
Housing & 8.72 & 8.33 & 9.04 \\
Heating and lighting & 5.63 & 5.51 & 5.41 \\
Tools for work & 0.64 & 1.16 & 2.31 \\
Intellectual education & 0.36 & 1.06 & 1.21 \\
Public safety & 0.15 & 0.47 & 0.88 \\
Health and recreation & 1.68 & 2.78 & 4.30 \\
Personal services & 0.19 & 0.16 & 0.40 \\
\hline
\end{tabular}

Source: lines 1-10: Table 6 in Engel (1857: 27)

expenditure make their own assumptions about the separability of preferences and the household budgeting process (Gorman 1959; Strotz 1957). These approaches assume that agents allocate total expenditure first to broad groups of goods, based on a price index for each group, and then further allocate expenditure within each of these groups, based on group individual prices and group expenditures. A benefit of these modern approaches is that they only rely on the assumption that households respond to price and income effects. However, Engel's approach suggests that it may be fruitful to let aggregation methods be also informed by scientific knowledge of the nature of consumer's needs and how these are satisfied. This strategy will not necessarily lead to the creation of more testable assumptions. It will, however, lead to the creation of more realistic assumptions that are at least consistent with what is known about the underlying motivations that drive household expenditure patterns.

The main conclusion of Engel's work was an observation about how the expenditure patterns of low income household reflect a ranking amongst needs (see Table 2). He explicitly claims that his results show that needs are not of equal importance to households, but rather that a hierarchy existed amongst needs (Engel 1857:27). As stated in the later book:

"Needs are not of the same rank. At the top stand those needs whose satisfaction is key to physical sustenance: nourishment, clothing, housing, heating and lighting and health. Of a second order follow: intellectual and spiritual care, legal protection and public safety, public provisions and assistance." (Engel 1895:8)

Engel argues that the observed hierarchy is in line with what typically happens in families experiencing a decline in income: When a family can not properly satisfy all their existing needs, they tend to sacrifice the satisfaction

\footnotetext{
3“'Allein die Bedürfnisse sind nicht alle von gleichem Range. Obenan stehen die von deren Befriedigung die physiche Erhaltung abhängt: Nahrung Kleidung, Wohnung, Heizung und Beleuchtung derselben und Gesundheitspflege. In Zwieter Linie folgen: Geistespflege, Seelsorge, Rechtsschutz und öffentliche Sicherhiet, Vor- und Fürsorge, Erholung und Erquickung."
} 
of higher order needs in order to satisfy more basic needs. Hence the lowering of income essentially acts as a litmus test on the consumer's priorities, in that it forces out expenditures related to needs that are less basic, and leaves those expenditures related to more fundamental needs. Therefore, it is possible to identify the most important needs by examining which types of expenditure dominate household spending at the lowest observed level of household income. The well-known 'Engel law' is based on his observation that expenditure on the need for nourishment increases as household income falls (Chai and Moneta 2010). Because of its importance, Engel reasons that a rough proxy for household living standards is the size of the budget share dedicated to nourishment: the lower it falls, the better off households are, as they are able to dedicate more expenditure to other, higher-order needs (Engel 1857:50).

All in all, Engel uses the concept of needs as an explanatory vehicle to account for 'Engel's law' and, more broadly, how household consumption patterns change as income rises. The idea that the need for nourishment is the most important need explains why low income households spend a large share of their budget on goods related to the satisfaction of this need. As households become more affluent, the budget share dedicated to other needs becomes more prominent as the household begins to dedicate more expenditure to the satisfaction of lower order needs.

\section{An evolutionary approach to needs}

The existence of a hierarchy amongst needs has the potential to provide an important account of how the composition of household expenditure systematically alters as households become more affluent. Since Engel's time, there has been considerable progress in both developing a theory of how consumer respond to marginal changes in price and their incomes, as well as the empirical analysis of household expenditure patterns (Deaton and Muellbauer 1980a; Aitken and Irongmonger 1995). However, a discussion of the underlying motivations of consumption is absent from much of this literature. It is widely recognized that marginalist consumer theory is unable to explain how budget expenditure shares will change in the face of rising income - as embodied in the basic shape of the Engel curve. As Prais puts it, "traditional theory of consumption deals only with infinitesimal changes, does not give any insight into the general shape of Engel Curves" (Prais 1953). More recently, Lewbel observes that contemporary models of demand systems "still fail to explain most of the observed variation in individual consumption behavior" (Lewbel 2007). The inescapable conclusion is that "influences other than current prices and current total expenditure must be systematically modeled if even the broad pattern of demand is to be explained in a theoretically coherent and empirically coherent way" (Deaton and Muellbauer 1980b:323).

A start to tackling this open question can be found in lexicographic demand systems (Day and Robinson 1973; Drakopoulos 1994; Earl 1983). Lexicographic choice theory explicitly models ordered preferences that constrain 
substitution possibilities between goods. In the recent literature, this idea has been used to model the concept of bounded rationality in the consumption context (Aversi et al. 1999; Nelson and Consoli 2010). Originating from Simon (1956), bounded rationality states that because agents have a limited amount of reasoning power and that decisions incur 'energy costs' (Loasby 1998:22), then any conception of the consumer 'perfectly optimizing' decisions would be logically impossible as it would require an infinite amount of time and thought.

Beyond modeling decision-making, lexicographic preference systems are also useful when considering how the broad composition of demand changes with rising income. In their strongest form, lexicographic preferences imply that the indifference curve is strictly vertical in certain regions, since consumers have no interest in substituting away from a certain good that serves first order needs until they have attained a critical quantity of this good. Only when this threshold is reached is it possible for consumers to substitute between this good and goods serving needs of a lower order. More weaker versions if lexicographic preferences model the same phenomenon via a change in the slope of the indifference curve, thus allowing some substitution between goods (Drakopoulos 1994). However, what is lacking in this approach is any hard predictions about precisely what type of expenditures consumers are less willing to substitute at low levels of expenditure.

Elsewhere, such a lexicographic structure of demand can be found implicitly hidden in many contemporary macroeconomic models of demand-driven structural change. These models examine what economic effects may result from changes in the composition of household expenditure patterns that take place as household rises. A key message of demand-driven structural change theory is that the industrial composition of growing economies can be altered by the manner in which household expenditure patterns change as household income rises (Metcalfe et al. 2006; Saviotti and Pyka 2008). This growing body of literature assumes that household expenditure on any particular good has an upper limit which causes the specific growth rate of demand faced by each sector to follow an S-shaped path, whereby demand growth will slow down and eventually cease as more households reach the saturation level of income (see inter alia Aoki and Yoshikawa 2002; Metcalfe et al. 2006; Foellmi and Zweimüller 2008; Saviotti 2001). ${ }^{4}$

The theoretical basis for the presence of saturation in demand patterns is the notion that some of the underlying needs that motivate consumption are 'satiable' as they can be effectively satisfied at some consumption level (see inter alia Menger 1871; Marshall 1890; Georgescu-Roegen 1954). Pasinetti argues that, because of the physiological nature of needs, they may be satisfied at certain income levels and the marginal utility of successive increments of the

\footnotetext{
${ }^{4}$ For a discussion of the extent to which saturation can be found across the wide variety of goods and services present in modern economies see Moneta and Chai (2010).
} 
same good tend to fall dramatically and can even become negative (Pasinetti 1981:72). The basic example is food. Once the consumer has eaten enough, they possess no willingness to pay for additional amounts of food. Once a need is satiated, the corresponding consumption expenditure dedicated to its satisfaction ceases to rise and additional increases in income are dedicated to the satisfaction of other needs which are not yet satiated. More recently, Witt $(2010,2001)$ makes some useful remarks on this issue from a naturalistic perspective. Similar to Engel, his starting point is the biologically evolved nature of humans, which has imprinted a certain number of 'basic needs' on the human genetic endowment. The degree to which a need influences consumption depends on the consumer's state of deprivation.

A general pitfall of the needs-based approach to consumption is that there is no clear consensus on precisely how many universally-shared needs exist. Needs schemas developed elsewhere have attempted to shed light on the functional nature of consumption, such as those developed by Maslow (1954), Galtung (1980) and Max-Neef (1991). Here it should be noted that there are important differences to the 'psychological' approach to defining the needs of consumers, compared to earlier 'physiological' approaches. For a detailed discussion of these see Deci and Ryan (1975). Psychological schemas are difficult to apply as they tend to include relatively difficult to observe higher order needs, such as the need for self determination. ${ }^{5}$ Moreover, because such needs have no basis in the biologically evolved nature of humans, it becomes hard to justify why they are universally shared by consumers and why they are fixed over time. In this respect, Witt argues that only needs with obvious reproductive value in times of fierce selection pressure should be considered as basic needs in the sense that they are innate and, indeed, they are commonly shared by humans (Witt 2010). In particular, he argues that these can be roughly identified as motivations associated with such activities as drinking, sleeping, eating, keeping body temperature, physical activity, sex, and seeking pain relief, shelter, affection, social recognition, sensory arousal, cognitive consistency, and achievement (Millenson 1967:386).

Another complication is the idea that the number of needs that agents possess may grow or decline over time. Beyond 'basic' needs, Witt conjectures that there exists another class of needs that are not universally shared, and may be acquired or lost through experience. Via the laws of associative learning (Hergenhahn and Olson 1997), formerly neutral stimuli that have repeatedly become associated with primary reinforcers may become reinforcing in their own right: for example, aesthetic tableware that has been regularly perceived while an agent has consumed food and enjoyed the company of others (Witt 2001:35). With enough experience, the consumer may find such tableware pleasing, even if it is not experienced in the company of food or friends. If

${ }^{5}$ For one attempt, see Jackson and Marks (1999). 
developed further, this approach could enable scholars to relax the assumption that consumers share the same set of needs and that these are constant over time, as different consumers with different learning histories will possess different sets of needs. Hence, an important phenomenon accompanying the growth of consumption could be the growth and diversification of acquired needs that have emerged and expanded as households become more affluent. This idea suggests that investigating the type of reinforcement to which consumers are exposed, as well the type of goods and services that are likely to become associated with this reinforcement, could yield insights into how the large diversity present in household consumption expenditure patterns may have arisen. ${ }^{6}$

If indeed it is feasible that certain consumer motivations are a product of the consumer's particular past experiences, this opens the door to understanding how the scale and quality of goods supplied in an economy can endogenously influence not only the knowledge that consumers possess, but also the motivations that stimulate consumers to purchase goods in the first place. In this respect, there is a growing awareness among contemporary scholars about how the structure of demand and supply may have important mutual influence on each other. For example, the economic historian de Vries (2008) points out that important historical changes in household economic activity led to increases in both the supply of market-orientated money earning activities and the demand for goods offered in the market place. Key here was that a change in consumer aspiration levels altered household's willingness to supply labor between 1650 and 1850 in such a way that households were prepared to work longer and harder than in previous generations. This 'industrious revolution' is an important macro-historical process necessary to understand patterns of long run economic development. Several other studies have highlighted the way in which the structure of technology and the nature of market institutions may foster creativity amongst consumers (Bianchi 2002) that, via the close interaction with producers, lead to the emergence of new product innovations (von Hippel 2005). In this sense, the search for consistent patterns of household expenditure patterns across large periods economic growth (see below) can be thought of as a way of examining the extent to which household consumption patterns are malleable and tend to be influenced by changing economic conditions. If indeed economic conditions play a strong role in shaping the nature of consumer needs, then it is highly unlikely that the composition of spending would stay constant over many decades of economic growth.

\footnotetext{
${ }^{6} \mathrm{~A}$ number of case studies have begun to study the evolving link between particular goods \& services and the underlying needs they serve. The general aim is to uncover general regularities in how product innovations may be linked to satiation of the needs original served by goods and services, such as food (Manig and Moneta 2009; Ruprecht 2005), shoes (Frenzel Baudisch 2006), tourism services (Chai 2011) and washing machines (Witt and Woersdorfer 2010).
} 


\section{Evidence for a hierarchy of needs}

This section examines what evidence exists for Engel's claims of a hierarchy amongst needs using modern household expenditure data. If Engel's conjecture is correct that certain needs of consumers are fixed and universallyshared across all consumers, then some possibility exists that a stable pattern of household expenditure could be found at the lowest observable levels of household income. We investigate this by using Engel's original classification schema in order to examine to what extent his results about the hierarchy of needs are robust. This does not imply that we fully agree with his proposed set of needs and how they relate to goods and services. Clearly, it is difficult to justify some of the assumptions Engel made in his classification methodology. However, given their historical precedence and the lack of a better alternative, we adopt Engel's classification methodology to see whether his findings about the existence of a hierarchy still hold. This exercise will shed light on the existence of a stable pattern in household consumption patterns. Yet the extent to which this stable patterns can be used as evidence for a hierarchy needs is an open question. In this regard, we leave it for future work to develop a more refined list of needs and an associated classification scheme for aggregating goods and services.

There are several foreseeable reasons why it is unlikely that the ordering of budget shares in modern consumption data is similar to that found by Engel in 1856. Clearly, consumer needs are not the only factor that influence relative levels of consumption expenditure. Changes in supply side conditions could lead to significant changes in expenditure patterns over time via the growth of production capacity and the realization of economies of scale, that would affect the cost of consumption. It is foreseeable that technological progress and increased competition may enable households to satisfy their most basic needs in a relatively inexpensive fashion compared to households of the 19th century. Furthermore, the difference in income between households observed in the 1850s and those observed in the present day are large. Since 1820, there has been an eightfold increase in world per capita income (Maddison 2001). As a result, it is possible that even at the lowest observed income level, household income may have increased sufficiently over time to lead to alterations in the order of budget shares due to expenditure on certain needs being subject to satiation at some real level of expenditure. In other words, if preferences are truly non-homothetic, then sufficiently large increases in household income over time can be predicted to cause major changes in the spending patterns at even the lowest observed household income level.

Using the classification scheme devised by Engel, we proceeded to recategorize and aggregate household expenditure data from the UK Family expenditure survey. We choose to use observations from 5 years that span over four decades 1961, 1970,1980, 1990 and 2000. These years were chosen for two reasons: First, we sought to cover a long time span in order to ensure that any results are not a consequence of conditions specific to any one particular sample year. Second, due to the time consuming nature of re-categorizing 
Table 3 Summary income statistics of three person household in FES data, 1960-2000

\begin{tabular}{llllll}
\hline & 1960 & 1970 & 1980 & 1990 & 2000 \\
\hline Number observations & 642 & 1218 & 1208 & 1106 & 990 \\
Mean real weekly total expenditure & $£ 13.81$ & $£ 42.23$ & $£ 125.71$ & $£ 314.05$ & $£ 468.18$ \\
Standard deviation & $£ 8.86$ & $£ 48.05$ & $£ 112.71$ & $£ 206.93$ & $£ 294.28$ \\
Lowest observed total expenditure & $£ 3.83$ & $£ 8.32$ & $£ 15.30$ & $£ 20.45$ & $£ 44.58$ \\
Highest observed total expenditure & $£ 271.84$ & $£ 1373.77$ & $£ 2006.60$ & $£ 2535.86$ & $£ 3789.67$ \\
\hline
\end{tabular}

Note: measured in pounds, where 2000 is the base year. The Retail Price Index (RPI - all items percentage change over 12 months) was used to derive real values.

expenditure using Engel's schema, the number of survey years used was limited to five. To avoid the complications arising from differences in household size, we focus on three person households, since these have the largest number of observations relative to other household sizes. ${ }^{7}$

Table 3 below reports the summary of income statistics. To control for changes in price levels, the Retail price (RPI - all items percentage change over 12 months) was used to derive real values. Average income (as proxied by total expenditure) has clearly risen considerably between 1960 and 2000, and the changes in the standard deviation of income indicate that there were also substantial changes in the income distribution of households. The budget shares for these expenditure grouping were then calculated for ten income deciles for each year included in the sample.

Table 4 reports results for the lowest income decile observed for each sample year. The most salient feature of these results is the surprising consistency of the budget shares across the four decades. Between 1960 and 1980 none of the budget shares changed by more than $2 \%$ : the budget share of expenditure dedicated to nourishment dropped marginally from 62 to $60 \%$, while the budget share of expenditure dedicated to clothing rose slightly from 8 to $10 \%$. Other small changes occurred in the budget shares relating to intellectual goods and heating and lighting expenditure. This stability in the household budget shares of expenditure occurred in spite of a large increase in the average real income of three-person households in the lowest income decile: the weekly average real total expenditure rose from 6.81 pounds in 1960 to 123.46 pounds in 2000 . It is only after 1980 that and significant changes can be observed: expenditure on nourishment declined significantly, while housing expenditure increased significantly. We note that the upward trend in housing

\footnotetext{
${ }^{7} \mathrm{We}$ avoided aggregating across households of different sizes as this would involve using equivalence scales that feature a priori assumptions about how the proportion of family spending dedicated to needs changes with family size. To check the robustness of our results, we aggregated spending data across different household sizes. We found similar results to those reported below, These results are available upon request. In the reclassification exercise, some unavoidable inaccuracies emerged, as there was insufficient information to properly allocate the expenditure category within Engel's schema.
} 
Table 4 Budget shares for the lowest income decile, 1960-2000

\begin{tabular}{lcccrr}
\hline Needs & 1960 & 1970 & 1980 & 1990 & 2000 \\
\hline 1. Nourishment & 62 & 60 & 60 & 40 & 38 \\
2. Clothing & 8 & 9 & 10 & 9 & 9 \\
3. Housing & 1 & 1 & 1 & 13 & 17 \\
4. Heating and lighting & 6 & 5 & 4 & 6 & 9 \\
5. Tools & 7 & 7 & 7 & 7 & 6 \\
6. Intellectual education & 3 & 3 & 1 & 0 & 6 \\
7. Public safety & 1 & 0 & 3 & 6 & 0 \\
8. Health and recreation & 3 & 4 & 1 & 1 & 0 \\
9. Personal services & 2 & 2 & 8 & 15 & 11 \\
10. All other & 7 & 9 & & & \\
\hline
\end{tabular}

Note: entries denote per cent of total expenditure.

expenditure budget shares reflects the substantial increase in house prices since the 1980s, reductions in the government provision of housing subsidies to low income households, as well as other well known measurement changes related to the manner in which housing expenditure was recorded in the UK Family Expenditure Survey (Tanner 1999).

Contrasting these results to Table 2, they appear to be surprisingly consistent with Engel's observed patterns. Expenditure on nourishment for the poorest observed category of workers was roughly $71 \%$ of total expenditure in 1856, while in 1960 it was $62 \%$ of total expenditure. In other words, the budget share of nourishment dropped by merely nine per cent in 104 years- a century which witnessed unprecedented economic growth in Europe and an eightfold increase in world per capita income (Maddison 2001).

More generally, the spending on needs that Engel identified as being key to physical sustenance consistently dominate low-income household consumption patterns across all sample years. Summed together, expenditure dedicated to the first order needs represents around $70 \%$ of total expenditure across the observed years 1960-2000. The budget share for heating and lighting in the contemporary data also appears to be roughly the same of what it was in the 19th century, although more recently this has increased which reflects the rising price of energy services. As such, these results provide evidence for the conjecture that a stable pattern of expenditure does exist at the lowest levels of observable household income, and has remained considerably stable in spite of the growth in real household income, as well as the goods and services available to households.

We use a comparison of means test to examine formally Engel's specific claim that needs related to physical sustenance, including nourishment, clothing, housing, heating and lighting and health, are of a higher order to needs related to intellectual spiritual care, legal protection and public safety, public provisions and assistance (see previous section). We do this by aggregating the relevant expenditure categories and performing two-sample mean-comparison test, where the hypothesis is that the mean expenditure dedicated to physical sustenance is greater than the mean expenditure dedicate to second order 
Table 5 Mean comparison test for lowest income decile, 1960-200

\begin{tabular}{lccccc}
\hline & 1960 & 1970 & 1980 & 1990 & 2000 \\
\hline $\begin{array}{c}\text { Lowest income decile } \\
\text { Mean expenditure dedicated } \\
\text { to physical sustenance }\end{array}$ & $7222.69^{* * *}$ & $1999.17^{* * * *}$ & $26576^{* * * *}$ & $67.42^{* * * *}$ & $90.41^{* * *}$ \\
$\begin{array}{c}\text { Mean expenditure dedicated } \\
\text { second order needs }\end{array}$ & 348.61 & 885.562 & 1721.41 & 2.96 & 7.78 \\
\hline
\end{tabular}

Note: Large differences in values arise across years due to changes in the reporting methods of the FES. Three stars indicate that hypothesis that the means of expenditure dedicated to sustenance is larger than the mean of expenditure dedicated to second order needs can not be rejected at the $\alpha=1 \%$ level of significance.

needs. Table 5 below shows that this can not be rejected at an $\alpha=1 \%$ level of significance. As such, it provides some evidence to support Engel's argument that expenditure dedicated to physical sustenance tends to dominate expenditures related to second order needs in the consumption patterns of low income households, and does so consistently over the four decades analyzed in this study.

\section{An Addendum to Engel's law}

We now turn to investigate the manner and pace at which the composition of household expenditure patterns evolve as household income levels rise. Previous studies using highly aggregated, national spending data have found preliminary evidence for a positive correlation between expenditure diversification and income (Falkinger and Zweimüller 1996; Theil and Finke 1983). However, these studies have used highly aggregated country level data in which inferences about the relationship between income and expenditure diversification have been drawn from comparing the aggregate expenditure patterns of a rich country to those of a poor country. To date, we are not aware of any study that has used actual household spending data to examine diversification patterns across a wide range of expenditure categories. So far, it appears that only diversification patterns within certain categories, e.g. food, have been studied (Thiele and Weiss 2003). Therefore, to gain a deeper understanding of how evenly total expenditure is distributed across expenditure categories at different household income levels, we use household level data and employ the Gini measure of inequality in order to show how it fluctuates across household income and time. If one accepts the notion that Engel's classification schema does, to some extent, measure the relative influence of certain needs on household expenditure patterns, then investigating changes in this distribution may provide some insight into how the hierarchy of needs changes household income rises.

We begin by examining the distribution of expenditure at high income levels. Table 6 reveals that, while nourishment is still the most dominant expenditure category, there is much more variability in the budget share of 
Table 6 Budget shares for the highest income decile, 1960-2000

\begin{tabular}{lcrrrr}
\hline Needs & 1960 & 1970 & 1980 & 1990 & 2000 \\
\hline 1. Nourishment & 28 & 21 & 23 & 15 & 16 \\
2. Clothing & 15 & 9 & 10 & 8 & 8 \\
3. Housing & 17 & 16 & 18 & 15 & 25 \\
4. Heating and lighting & 2 & 2 & 1 & 0 & 9 \\
5. Tools & 17 & 7 & 10 & 14 & 10 \\
6. Intellectual & 3 & 3 & 4 & 5 & 3 \\
7. Public safety & 2 & 1 & 9 & 7 & 0 \\
8. Health and recreation & 7 & 11 & 2 & 1 & 9 \\
9. Personal services & 2 & 2 & 24 & 33 & 2 \\
10 All other & 8 & 29 & & & 18 \\
\hline
\end{tabular}

Note: Entries denote per cent of total expenditure.

household expenditure on tools, housing, and clothing. Compared with the highest income level observed by Engel, the budget expenditure on nourishment has more than halved, from $62.42 \%$ in 1856 to $27.86 \%$ in 1960 . Between 1960 and 2000, considerable fluctuations can be found in the budget share related to shelter, tools and 'all other' cateogries.

Comparing these results with the expenditure patterns of contemporary low income households (see Table 5), an interesting pattern emerges. Clearly, as predicted by Engel's Law, food expenditure dedicated to food is much lower relative to low-income households. Also, in the lowest income decile there is a very uneven distribution of expenditure as most of the expenditure is concentrated in expenditure related to nourishment. At high income levels, household expenditure appears to be distributed much more evenly across the different expenditure categories. To get a more precise picture of how unevenly household expenditure is distributed across these expenditure categories, we calculate the Gini coefficient, which is a measure of the inequality of a distribution, a value of 0 expressing total equality and a value of 1 maximal inequality. Using Deaton's (1997) formula:

$$
G=\frac{N+1}{N-1}-\frac{2}{N(N-1) \mu}\left(\sum_{i=1}^{n} P_{i} X_{i}\right)
$$

where

$N$ is the set of consumption expenditures (See Table 1)

$\mu$ is the mean budget share of the set

$P_{i} \quad$ is the budget share rank of expenditure $i$ with budget share $X_{i}$.

The results, as found in Table 7, reveal what appears to be evidence for a general regularity describing the way in which consumption expenditure becomes more diversified as households become more affluent. ${ }^{8}$ As household income grows, not only is there a decline in the budget share dedicated to

\footnotetext{
${ }^{8}$ This finding should be interpreted as a "generic invariance" in the statistical properties of consumption behavior in the spirit advocated by Aversi et al. (1999:384).
} 
Table 7 Gini coefficient for expenditure shares, 1960-2000

\begin{tabular}{llllll}
\hline & 1960 & 1970 & 1980 & 1990 & 2000 \\
\hline Lowest income decile & 0.74 & 0.75 & 0.76 & 0.61 & 0.61 \\
Middle income decile & 0.69 & 0.66 & 0.68 & 0.60 & 0.56 \\
Highest income decile & 0.53 & 0.52 & 0.54 & 0.48 & 0.54 \\
\hline
\end{tabular}

nourishment, but household expenditure is distributed across consumption expenditure categories in a more even fashion. This is reflected in the fact that, across all of the observed years, the Gini coefficient for the highest decile is lower than the Gini coefficient for the lowest income decile. This indicates that total expenditure is distributed more evenly across expenditure categories at high income levels than it is at low income levels. In other words, the budget share of the various expenditure categories exhibit a tendency to converge to a common level, as household income increases. This implies that diversification of household expenditure does not take place in such a way that any one particular non-food expenditure category tends to dominate other non-food expenditure categories. Rather, it appears that diversification takes place in such a way that additional income is distributed in increasingly equal proportions across non-food expenditure categories.

It should be noted that this finding is not encapsulated in Engel's law, which describes how the budget share of household expenditure on food declines in response to an increase in household income. While Engel's law does imply that the budget share of non-food expenditure will rise, it has no implications for how consumption expenditure will be distributed across non-food categories. The above finding suggests that, as the food budget share declines, the budget shares of all other non-food expenditure categories will tend to converge. ${ }^{9}$ To attain an increasingly even distribution across these expenditure categories, there must be an additional regularity at work that relates to how expenditure is distributed in increasingly equal proportions across different expenditure categories. In this respect, we claim this result to be an additional insight into understanding the manner in which the composition of household expenditure changes as household income grows. Of course, it is likely that this result will not hold if expenditure is highly aggregated into two or three categories, such as 'food' and 'non-food', or food, goods and services. We speculate that the finding holds if at least four different expenditure categories are specified. ${ }^{10}$

\footnotetext{
${ }^{9}$ This result is also different from Prais' (1953) statement that, as income rises, a greater number of goods will enter the household consumption basket (see Jackson 1984). The fact that a greater number of goods enter the consumption basket does not imply that there will be a more even distribution across expenditure categories. It is a possible that the number of items found in the household consumption basket increases, without affecting the distribution of total expenditure across expenditure categories.

${ }^{10}$ Regarding how sensitive these results are to demographic factors, we found that these results were robust when comparing ECs for households of different sizes (two and three person households). For reasons of space we do not report these results here. They are available on request.
} 
In terms of understanding how the order of needs changes as household income rises, this finding also suggests that, if Engel's expenditure categories are an accurate reflection of the influence of needs, the actual hierarchy of needs appears to have a very different character to those proposed by social scientists such as Maslow (1954). Rather than there being a clear order among several needs, it appears that there exists only an order to the extent that the need for nourishment predominates over other needs at low income levels, but no other needs clearly predominate at higher income levels.

An examination of how these Gini coefficient changes across time (see Fig. 1) reveals a downward trend among households located in the lowest income decile, from around 0.73 in 1960 to approximately 0.60 in 2000. Among households in the middle income decile, the Gini coefficient also exhibited a downward trend, from around 0.70 in 1960 to around 0.57 in 2000. This finding suggests that the expenditure patterns of households located in these income deciles are becoming increasingly diversified over time. Thus, while we found evidence for the existence of a stable pattern of household expenditure at low income households in the previous section, these results suggest that it would be misleading to conclude that no significant changes have occurred

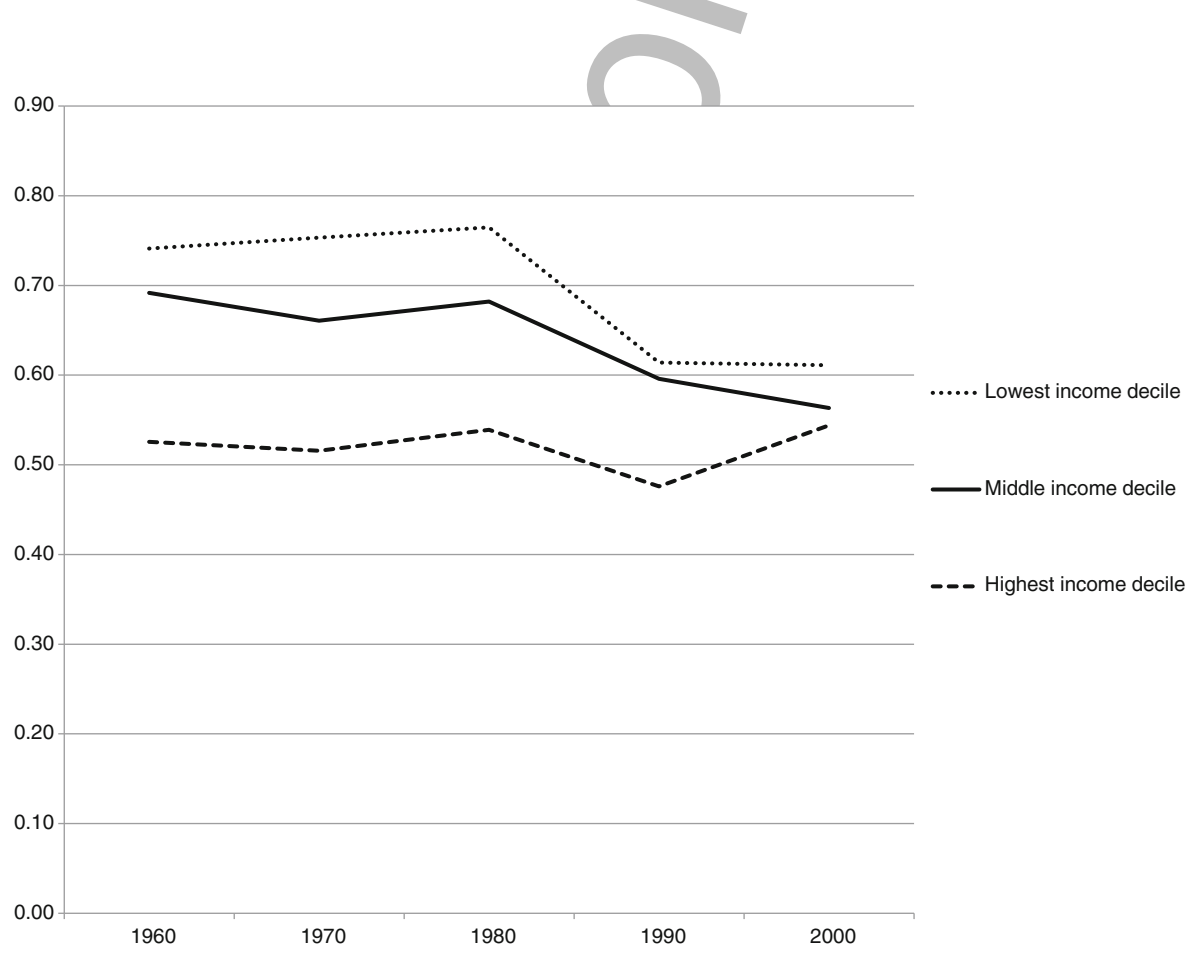

Fig. 1 Evolution of Gini coefficients, 1960-2000. Gini coefficients are calculated to measure how evenly total expenditure is distributed across expenditure categories. This is done separately for low, middle and high income households. The results show that, as household income increases, total expenditure tend to become more evenly distributed across expenditure categories. Note that differences between high income and low income households appear to be declining over time 
in the expenditure patterns of low income households. This negative trend Gini coefficients appears to indicate an acceleration in the rate at which household expenditure patterns become diversified. Historically, it was only in the expenditure patterns of high income households that one can find a large amount of expenditure diversity. However, this results suggest that this is increasingly not the case in the modern era, as the household expenditure patterns of middle and low income households have become increasingly diversified across expenditure categories.

Finally, it is also interesting to note that the relative differences in how unevenly spread household expenditure patterns are between low income and high income households appear to be falling over time. In 1960 the difference in the Gini coefficient between low income and high income households was 0.21 . This dropped to 0.07 in 2000 . To some extent, a factor contributing to this drop is the rise of housing expenditure, which has a large influence on the expenditure patterns of high income households and is mainly a result of rapidly increasing house prices in the UK (as discussed above). Nevertheless, the fact that low income households are increasingly able to distribute their expenditure patterns more evenly across Engel's expenditure in a manner that is increasingly similar to the expenditure patterns of high income households, may provide new information about household living standards and how they differ across income groups.

\section{Needs and Engel curves}

Finally, we turn to consider what the shape of ECs may reveal about the relationship between the goods and services and the range of underlying needs they served. In doing so, we begin to tackle one of the major shortcomings of Engel's original approach, namely the a priori assumptions made about the relationship between goods and services and the needs they served. ${ }^{11}$ In terms of how household expenditure patterns may evolve over time, these assumptions are particularly vulnerable in light of the rapid pace at which product innovations take place in modern market economies which may take place in precisely such a way so as to ensure goods serve multiple needs (Witt 2001). Even holding time constant and only thinking about how expenditure patterns change across different household income levels, these assumptions are vulnerable. Given the range of goods and services that are present in low income versus high income expenditure patterns, it is clear that many luxury versions of goods, such as luxury pens, luxury wristwatches, luxury cars and so on, do not serve the same needs as their relatively cheaper counterparts. To uncover comprehensively the link between goods and the needs they serve, one would require detailed micro level data on consumer expenditure, product

\footnotetext{
${ }^{11}$ Similar assumption are made in Jackson and Marks (1999).
} 
characteristics and information on individual's consumption experiences, which are not available on the aggregate level.

Nevertheless, an interesting question is whether it is possible to uncover empirically any insights about this relationship from the shape of ECs. The EC describes the relationship between an expenditure category and income. It is typically expressed as a share of total expenditure. The EC relative to a particular expenditure $g$ is estimated by regressing the budget share of expenditure $b_{i}$ allocated to $g$ on total expenditure $x_{i}$ :

$$
b_{i}=m\left(x_{i}\right)+\epsilon_{i}
$$

The subscript $i$ refers to households $1, \ldots, n$. The broad shape of the EC is commonly used to infer the income elasticity of a good. It is notable that, for much of the twentieth century, the parametric approach to estimating ECs was dominant, which required researchers to make a priori assumptions about the shape of the EC. Via the gradual shift away from linear towards log-linear and eventually nonlinear functional forms (Banks et al. 1997; Prais 1953), some consideration was given to functional forms that imposed a saturation level of expenditure (Aitchison and Brown 1954).

In the following, we adopt a nonparametric approach in which there is more scope to discovering and verifying general regularities because the shape of the regression curve is derived from the data without assuming any functional form a priori (see Engel and Kneip 1996 for a discussion). It should be noted that the nonparametric approach cannot avoid dealing with two major problems that must be faced when working with household expenditure data. First, the functional form is influenced by the distribution of observations. As most household expenditure surveys have fewer observations at high levels of household income, some doubt may be cast on the properties of nonparametric ECs at these levels. However, in the case of the UK Family Expenditure Survey, Tanner (1999) studied the reliability of FES expenditure data by comparing it to spending figures found in the UK National Accounts. She found that the ratio of non-housing total FES expenditure to non-housing total expenditure in the National Accounts was around 90\% between 1974 and 1992. ${ }^{12}$

A hypothesis about how the shape of the EC shape may reveal information about the set of needs that a good serves can be found in the literature on lexicographic preferences. This literature suggests that the more needs a particular expenditure category serves, the greater are the number of changes one would expect to observe in the slope of the EC (for details see Day and Robinson 1973; Drakopoulos 1994). Consequently, when examining the shape

\footnotetext{
${ }^{12}$ This compares favorably to the US Consumer Expenditure Survey (CES) in which Slesnick (1992)found that 1989 per capita total expenditure only captures $65 \%$ of per capita total expenditure recorded in the National Income and Product Accounts.
} 
of ECs estimated with nonparametric techniques, one would to expect find some common properties in the shape of the EC for expenditure categories that serve multiple needs, relative to goods that serve a smaller range of needs. To this end, we use household expenditure data to investigate whether any similarities can be found among the shape of Engel curves for goods that we hypothesize tend to serve a relatively limited range of needs.

In particular, we hypothesize that certain perishable goods, such as food, tobacco and alcohol, tend to serve a relatively limited range of needs, while other durable goods and services tend to serve a relatively wider range of needs. Perishable goods can be thought of as 'first order' goods, in that they possess a specific purpose and are directly used by consumers to satisfy their needs. According to Menger (1871), these can be distinguished from higher order goods that do not directly satisfy consumers' needs, but are instead used by consumers to transform other goods in a consumption process (e.g. an oven is used to make cake which is then consumed).${ }^{13}$ Menger notes that the use of such higher order goods is heavily dependent on the consumer's knowledge and their ability to combine its use with other higher order goods and services (e.g. a consumer must use electricity to power the oven) ${ }^{14}$ In addition, another higher order good used by modern households is services. In using services, consumers are buying a set of processing operations to be undertaken by a service provider (Gallouj and Weinstein 1997). For example, instead of cooking their own meals, cleaning their own houses, or fixing their own cars, consumers may purchase services to undertake these activities. In other cases, services are used because consumers seek 'expert' advice, e.g. medical and legal services, which are required in order to take advantage of knowledge accumulated in society (Earl and Potts 2004). A major part of the growth in the consumption of services can be viewed as an outcome of an outsourcing exercise on the part of consumers who have little time or high opportunity costs to manipulate lower order goods and services themselves (Lindner 1970).

Because of the relatively specific and direct fashion in which they are used to satisfy needs, we argue that lower order goods are less likely to serve a wide range of needs in comparison to higher order goods. For example, food only describes perishable and edible materials that are all closely linked to the need for nourishment. On the other hand, higher order goods such as services can include everything from hairdressing, lawyer's fees, catering, mechanical services, music lessons that relate to a wider range of needs as social recognition, transport, legal protection and intellectual fulfilment. The

\footnotetext{
${ }^{13}$ To be distinguished from Becker's (1996) approach; see Steedman (2001) and Elster (1997).

${ }^{14}$ Similarly, Witt (2001) distinguishes between goods used to directly satisfy needs, such as food and drink, which he calls 'basic inputs' (2001). They are non-renewable in that once they have been used, they cannot be used again. On the other hand, 'tools' are different in that they include relatively more durable goods such as ovens and clothing which are used by consumer to produce lower order goods(see Witt and Woersdorfer 2010).
} 
intangible nature of service and the tendency for these to be modified in accordance with the consumer's specifications implies they possess a greater flexibility in serving a wide range of needs. Perhaps some forms of food can be used as a status signalling device (caviar) or as an aphrodisiac (oysters), but it is highly unlikely that food can serve such needs as legal protection or transport. Similar arguments can be made about other lower order goods such as alcohol and tobacco in that they are perishable goods with unique material properties that are used directly in the satisfaction of needs. Thus we build a preliminary hypothesis that basic inputs that serve a relatively limited set of needs will possess relatively similar EC shapes.

Hypothesis A: Engel curves for lower order goods possess shapes that are more similar to each other than to the shapes of Engel Curves for higher order goods.

Hypothesis B: Engel curves for higher order goods possess shapes that are more similar to each other than to the shapes of Engel Curves for lower order goods.

It should be noted that there are other possible explanations that account for the shape of ECs. For example it is common in the literature to assume that all consumer's face the same price (the law of one price). However, regional differences in prices across geographic locations with different socioeconomic conditions may influence the shape of the Engel curve. Also, the EC shape may be the product of the distribution of observations. Especially at high income levels, the density of observations decreases rapidly, which tends to influence the shape of ECs at high income levels. In this regards, the rank correlation method (described below) used in this paper takes this into account, as it allocates a higher weighting to observation at lower income levels.

In contrast to Engel's concept of hierarchy which is couched in terms of an order of needs, the concept of lower and higher order goods is linked more to the manner in which goods are used by consumers to satisfy any given need. Both higher and lower order goods can thus be found within the expenditure dedicated to any given need. For this reason, we can not use the same classification method used in the previous section. Instead, to test these hypotheses, we classify goods according into thirteen aggregate expenditure categories found in the UK Family Expenditure Survey. The data is taken from the UK Family Expenditure Survey 1986-2001 jointly with the expenditure and food survey (EFS) 2002-2006. The data are about household expenditures on various categories of goods and services. Each year, approximately 7,000 households were randomly selected, and each of them recorded expenditures for two weeks. We are able to recover information about total expenditures and expenditures on thirteen aggregated categories: (1) housing (net); (2) fuel, light, and power; (3) food; (4) alcoholic drinks; (5) tobacco; (6) clothing and footwear; (7) household goods; (8) household services; (9) personal goods and services; (10) motoring, fares and other travel; (11) leisure goods; and (12) 
leisure services. ${ }^{15}$ In order to have samples of households which are demographically homogeneous, we only consider families which have a number of members between two and three. Families of this type are approximately 3,000 each year.

We estimate the ECs in a nonparametric fashion for the 13 categories using the kernel smoothing method proposed by Gasser and Müller (1984) and Gasser et al. (1991). This estimator, besides having an asymptotic bias that is nevertheless preferable to the Nadaraya-Watson estimator, has the advantage of being easily applicable to the problem of estimating the derivatives of regression functions. The kernel function used is a fourth-order kernel, and the bandwidth parameter is chosen via the plug-in approach proposed by Herrmann (1997), which has the advantage of being able to deal with heteroscedasticity.

To measure the similarity in shape between estimated regression curves, we use the rank correlation method proposed by Heckman and Zamar (2000). In contrast with the $L_{2}$ distance between two functions $m_{1}$ and $m_{2}\left(\int\left\{m_{1}(x)-\right.\right.$ $\left.\left.m_{2}(x)\right\}^{2}\right)$, the rank correlation is able to capture qualitative features of the curves such as kinks and spikes (cf. Marron and Tsybakov 1995). But what does it mean that two ECs (derivatives or variances) $m_{1}(x)$ and $m_{2}(x)$ have the same shape? They have the same shape if there exists a strictly increasing function $g$ such that $m_{1}(x)=g\left\{m_{2}(x)\right\}$, that is the plot of $y=m_{1}(x)$ is the same of $y=m_{2}(x)$ after a deformation of the $y$ axis. The measure of similarity proposed by Heckman and Zamar presupposes the definition of a probability measure $\mu$ on the the interval in which $m_{1}(x)$ and $m_{2}(x)$ are defined (which is the unit interval after standardizing the data). We use as measure $\mu(A)=$ $(\# x \in A) /(\# x \in[0,1])$ (that is, the proportion of $x$ points that are in $A$ ), for any subinterval $A$ of the unit interval. The rationale for using this measure is to give more weight to the portion of the curve for which there are more observations. The rank correlation measure between $m_{1}(x)$ and $m_{2}(x)$ is defined as:

$$
\rho_{\mu}\left(m_{1}, m_{2}\right)=\frac{\int\left\{r^{m_{1}}(w)-R^{m_{1}}\right\}\left\{r^{m_{2}}(w)-R^{m_{2}}\right\} d \mu(w)}{\sqrt{\int\left\{r^{m_{1}}(w)-R^{m_{1}}\right\}^{2} d \mu(w) \int\left\{r^{m_{2}}(w)-R^{m_{2}}\right\}^{2} d \mu(w)}},
$$

where $r^{m_{1}}(x)=\mu\left\{t: m_{1}(t)<m_{1}(x)\right\}+\frac{1}{2} \mu\left\{t: m_{1}(t)=m_{1}(x)\right\}$ and $R^{m_{1}}=\int r^{m_{1}}(w)$ $d \mu(w)\left(r^{m_{2}}(x)=\mu\left\{t: m_{2}(t)<m_{2}(x)\right\}+\frac{1}{2} \mu\left\{t: m_{2}(t)=m_{2}(x)\right\}\right.$ and $R^{m_{2}}=\int r^{m_{2}}(w)$

\footnotetext{
${ }^{15}$ The 12 categories, together with "miscellaneous and other goods", add up to total expenditures. From 1987 to 2006 the survey contains a macro-code for each of the 13 categories. For 1986, the FES contains macro-codes only from the first six categories (from housing to clothing and footwear), plus other macro-categories which are not consistent with the other seven categories listed above (household goods, household services, personal goods and services, motoring, fares and other travel, leisure goods, and leisure services). We thus constructed, for 1986, these seven macro-categories aggregating micro-categories (disaggregate expenditures) in order that they be consistent with the way they are formed in the years 1987-2006.Due to the quality of the data, it was not possible to control for other factors, such as geographic location. For a discussion of the empirical significance of these socio-demographic factors, we refer the reader to Calvet and Common (2003) and references therein.
} 


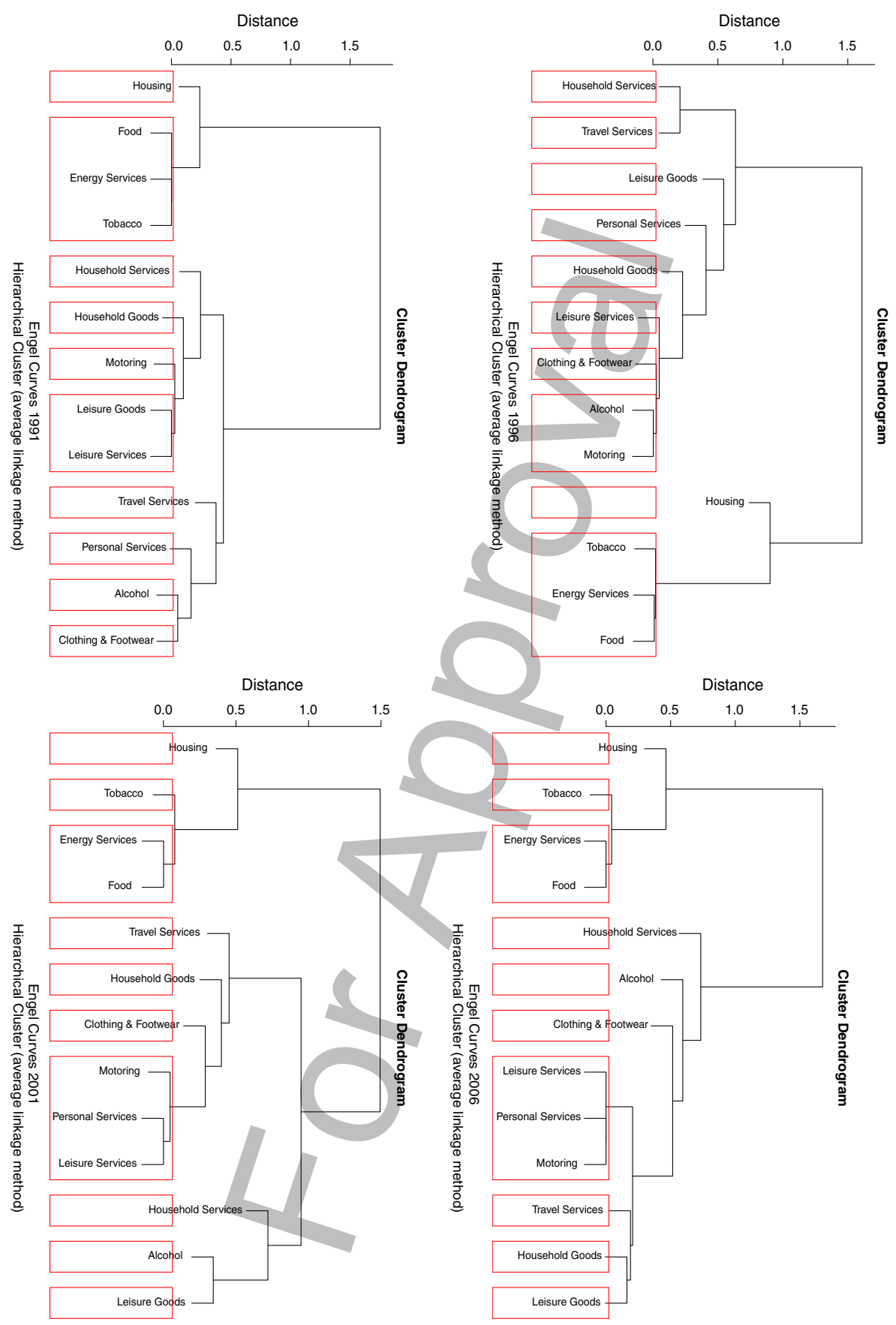

Fig. 2 Cluster Analysis of EC Shapes, 1991-2006. Note: A separate cluster analysis was undertaken for each year between 1986 and 2006. This figure above displays results for 1991, 1996, 2001 and 2006. Results for other years available upon request 
$d \mu(w))$. A consistent estimator of $\rho_{\mu}$ is given by Heckman and Zamar (2000:137). Having calculated these distances for each year under observation, a good overview of the magnitude of differences in EC shapes among the expenditure categories is attained via cluster analysis. We perform a hierarchical cluster analysis using as distance measure $d=\left(1-\rho_{\mu}\right) .{ }^{16}$

In terms of Hypothesis A, the cluster analysis reveals that the EC shapes for two of the three hypothesized lower order goods possess a relatively similar shape across the observed years (1986-2006). In 14 out of the 20 years observed, the ECs for food and tobacco were located within the same cluster at a very low height; see for example the cluster dendrogram for 1991 and 1996 in Fig. 2. In the remaining six years, food and tobacco still display relatively similar shapes, and tend to be situated in the same cluster at a relatively low height of 0.2; see, for example, the cluster dendrogram for 2001 and 2006 in Fig. 2. It was also found that the shape of the EC for alcohol was found to be relatively dissimilar to food and tobacco throughout the observed time period. Interestingly, a surprising result was that there is also a tendency for Energy Services to be consistently clustered with food, alcohol or tobacco. This category includes household expenditure on fuel, light and power which are used for cooking, heating and lighting. It is interesting to note the essentially perishable nature of this type of expenditure. All in all, it appears there is some preliminary evidence for the Hypothesis A that the Engel curves for lower order goods possess shapes that do appear to be more similar to each other, relative to the shapes of ECs for lower order goods.

In terms of Hypothesis B, the results are less promising. No discernable clusters of higher order goods and services emerge consistently across the observe time period. There is a weak tendency for the ECs of personal services and leisure services to possess similar shapes, as they appear in the same cluster at a very low height in four out of the 20 years observed; see for example the cluster dendrogram for 2001 and 2006 in Fig. 2. In an additional seven years, these two categories appear in the same cluster at the height of 0.5 . None of the other higher order goods and services, such as leisure goods, household goods and travel services display any tendency to exhibit a similar EC shape. All in all, these results suggest that hypothesis B can be rejected in that the Engel curves for higher order goods possess shapes do not appear to be more similar to each other, relative to the shapes of ECs for lower order goods.

\section{Conclusion}

This paper has taken a small step towards finding evidence for, and understanding the implications of, the existence of a hierarchy among the needs of consumers. Our results reveal that income patterns of low income households

\footnotetext{
${ }^{16}$ Note that since $-1 \leq \rho_{\mu} \geq 1$ we have $0 \leq d \geq 2$.
} 
are remarkably stable over several decades: a stability that could be attributed to the basic needs of consumers which are the product of the biological evolution. In particular, expenditure classified by Engel as being related to a group of needs that together constitute physical sustenance is significantly larger than expenditure on other, lower order needs.

Moreover, we examined the manner in which rising household income affects the distribution of total expenditure across expenditure categories. Our results reveal that, as household income rises, household expenditure is distributed across these expenditure categories in an increasingly even fashion. In other words, the budget share of the various expenditure categories exhibits a tendency to converge to a common level as household income increases. If indeed Engel's classification schema is broadly accurate in classifying goods and services according to the underlying needs they serve, this finding suggests that a hierarchy of needs appears to consist of two levels, in that it is only the most important needs, the need for nourishment, that appears to dominate other needs. There appears to exist no order between other, lower order needs. We also observed that, across time, an increase in the ability for households located at the low and medium income deciles to diversify their consumption patterns. An important research question for future work should uncover what supply and demand factors are responsible for this convergence. This would involve accounting for the effects of the lexicographic nature of household preferences on the demand side, as well as important qualitative differences in the nature of goods that are purchased by high and low income households (Witt 2001).

In sum, there is a great potential in adopting Engel's approach to studying changes in consumption through understanding the nature of the consumer's needs, their basis in human biology, and how their influence on consumption changes as household income increases. In particular, this may shed more light on how economic growth can lead to significant endogenous changes in the composition of household demand which, in turn, may have important implications for how the industrial composition of economies undergo transformation as they grow. At the same time, several important obstacles facing this approach still remain. Precisely how many needs are there? Do the set of needs possessed by consumers change significantly over time as a result of their past experiences? If we are to avoid making the same a priori assumptions that Engel made 150 years ago, it is also important to conduct work on developing a plausible way of uncovering empirically the relationship between particular goods and the needs they serve. This paper has yielded some preliminary evidence for the hypothesis that goods that serve a relatively limited range of needs, such as food and tobacco, tend to possess Engel curves with similar shapes, in comparison to the shapes of Engel curves of other goods and services that serve a wider range of needs.

All in all, while the challenges facing this approach are considerable, it should be remembered that the potential reward is large: To date, there exists no proper explanation for the shape of Engel curves and the income elasticity of goods and services that is properly couched in terms of how the behavior 
of individual households changes with rising income. An important task for progressing any science is to develop theories within which discovered laws have their place. As Engel himself recognized, an appropriate account for these shapes begins with a consideration of the motivations of consumption, and how these tend to change as households become more affluent. For evolutionary economists, this represents an opportunity to highlight the benefits of adopting a new approach to economics, since the observed stability of low income household expenditure observed across four decades suggests that the needs driving these regularities are inherent and linked to the evolved, biological nature of humans. Thus, what Engel's approach ultimately offers us is the beginning of a comprehensive theoretical framework that can account for the manner in which household expenditure patterns evolve as household income rises.

Acknowledgements We would like to thank Ulrich Witt, Paolo Saviotti, Giorgio Fagiolo, Nicholas Rohde, Liana Wortley, the anonymous referee who provided comments on the paper during the submission process, the participants at the 13th conference of the International Joseph A. Schumpeter Society International Schumpeter Society held in Aalborg (2010), as well members of the Evolutionary Economics Group at the Max Plank Institute of Economics, for very useful comments. We thank the UK Data Archive for providing access to the UK Family Expenditure Survey. The usual disclaimer applies.

\section{References}

Aitchison J, Brown JAC (1954) A synthesis of Engel curve theory. Rev Econ Stud 22(1):35-46 Aitken CK and Irongmonger DS (1995) Household time use surveys. Aust Econ Rev 28:89-92

Aoki M, Yoshikawa H (2002) Demand saturation-creation and economic growth. J Econ Behav Organ 48:127-154

Aversi R, Dosi G, Fagiolo G, Meacci M, Olivetti C (1999) Demand dynamics with socially evolving preferences. Ind Corp Change 8:2

Banks J, Blundell R, Lewbel A (1997) Quadratic Engel curves and consumer demand. Rev Econ Stat 79(4):527-539

Becker GS (1996) Accounting for tastes. Harvard University Press, Cambridge, MA

Bianchi M (2002) Novelty, preferences and fashion: when new goods are unsettling. J Econ Behav Organ 47:1-18

Calvet L, Common E (2003) Behavioral heterogeneity and the income effect. Rev Econ Stat 85(3):653-669

Chai A (2011) Consumer specialization and the romantic transformation of the British grand tour of Europe. J Bioecon 13:181-203

Chai A, Moneta A (2010) Retrospectives: Engel curves. J Econ Perspect 24(1):225-240

Day R, Robinson S (1973) Economic decision and the $L^{* *}$ utility. In: Cochrane J and Zeleny M (eds) Multiple criteria decision making. University of South Carolina Press, Colombia

Deci E, Ryan R (1975) Intrinsic motivation and self-determination in human behavior. Plenum Press, New York

Deaton A (1997) Analysis of household surveys. Johns Hopkins University Press, Baltimore

Deaton A, Muellbauer J (1980a) Economics and consumer behavior. Cambridge University Press, Cambridge

Deaton A, Muellbauer J (1980b) An almost ideal demand system. Am Econ Rev 70:312-326

de Vries J (2008) The industrious revolution. Cambridge University Press, Cambridge

Drakopoulos SA (1994) Hierarchical choice in economics. J Econ Surv 8(2):133-153

Ducpétiaux E (1855) Budgets économiques des classes ouvriéres en Belgique. Bruxelles 
Earl P (1983) The Economic Imagination. Wheatsheaf Books, Brighton

Earl P, Potts J (2004) The market for preferences. Camb J Econ 28:619-633

Elster J (1997) More than enough. Univ Chic Law Rev 64:749-764

Engel E (1857) Die produktions- und consumtionsverhältnisse des Königreichs Sachsen. Reprinted in Bull Inst Int Stat (1895) 9:1-54

Engel E (1895) Das Lebenskosten Belgischer Arbeiterfamilien früeher und Jetzt. Bull Inst Int Stat 9:1-124

Engel J, Kneip A (1996) Recent approaches to estimating Engel curves. Journal of Economics 63(2):187-212

Falkinger J, Zweimüller J (1996) The cross-country Engel curve for product diversification. Struct Chang Econ Dyn 7:79-97

Frenzel Baudisch A (2006) Continuous market growth beyond functional satiation. Papers on Economics and Evolution 0603

Foellmi R, Zweimüller J (2008) Structural change, Engel's consumption cycles and Kaldor's facts of economic growth. J Monet Econ 55(2):1317-1328

Gallouj F, Weinstein O (1997) Innovation in services. Res Policy 26:537-556

Galtung J (1980) The basic needs approach. In: Lederer K (ed) Human needs. Oelgeschlager, Gunn and Hain, Cambridge

Gasser T, Kneip A, Köhler W (1991) A flexible and fast method for automatic smoothing. J Am Stat Assoc 86(14):643-652

Gasser T, Müller HG (1984) Estimating regression functions and their derivatives by the Kernel method. Scand J Statist 11:171-185

Georgescu-Roegen N (1954) Choice, expectation and measurability. Quart J Econ 68:503-534

Gorman M (1959) Separable utility and aggregation. Econometrica 27:469-481

Heckman NE, Zamar RH (2000) Comparing the shapes of regression functions. Biometrika 87(1):135-144

Herrmann E (1997) Local bandwidth choice in Kernel regression estimation. J Comput Graph Stat 6(1):35-54

Hergenhahn B, Olson M (1997) An introduction to theories of learning. Prentice Hall, New Jersey

Jackson L (1984) Hierarchic demand and the Engel curve for variety. Rev Econ Stat 66:8-15

Jackson T, Marks N (1999) Consumption, sustainable welfare and human needs - with reference to UK expenditure patterns between 1954 and 1994. Ecol Econ 28:421-441

Lewbel A (2007) Engel Curves. The New Palgrave Dictionary of Economics

Loasby BJ (1998) Cognition and innovation. In: Bianchi M (ed) The active consumer: novelty and surprise in consumer choice. Routledge, London

Lindner S (1970) The harried leisure class. Columbia University Press, New York

Maddison A (2001) The world economy: a millennial perspective. OECD, Paris

Manig C, Moneta A (2009) More or better? Quality versus quantity in food consumption. Papers on Economics and Evolution 0918

Marron JS, Tsybakov AB (1995) Visual error criteria for qualitative smoothing. J Am Stat Assoc 90(430):499-507

Marshall A (1890) The principles of economics. Prometheus Books, London

Maslow A (1954) Motivation and personality. Harper and Row, New York

Max-Neef M (1991) Human-scale development- conception, application and further reflection. Apex Press, London

Menger C (1871) Grundsätze der Volkswirthschaftslehre. Wilhelm Braumüller, Wien

Metcalfe S, Foster J, Ramlogan R (2006) Adaptive economic growth. Camb J Econ 30:7-32

Millenson JR (1967) Principles of behavioral analysis. New York: Macmillan

Moneta A, Chai A (2010) The evolution of Engel curves and its implications for structural change. Discussion Paper, Griffith University

Nelson R, Consoli D (2010) An evolutionary theory of household consumption behavior. J Evol Econ 20:665-687

Pasinetti L (1981) Structural change and economic growth. Cambridge University Press, Cambridge

Prais SJ (1953) Non-linear estimates of the Engel curves. Rev Econ Stud 20(2):87-104

Ruprecht W (2005) The historical development of the consumption of sweeteners a learning approach. J Evol Econ 15:247-272

Saviotti P (2001) Variety, growth and demand. In: Witt U (ed) Escaping satiation. Springer, Berlin, pp 115-138 
Saviotti P, Pyka A (2008) Product variety, competition and economic growth. J Evol Econ 18(3):323-347

Simon H (1956) Rational choice and the structure of the environment. Psychol Rev 63:129-138

Slesnick D (1992) Aggregate consumption and saving in the postwar United States. Review Econ Stat 18(3):323-347

Steedman I (2001) Consumption takes time. Routledge, London

Stigler GJ (1954) The early history of empirical studies of consumer behavior. J Polit Econ 62(2):95-113

Strotz RH (1957) The empirical implications of a utility tree. Econometrica 25:269-280

Theil H, Finke R (1983) The consumer's demand for diversity. Eur Econ Rev 23:395-400

Thiele S, Weiss C (2003) Consumer demand for food diversity: evidence for Germany. Food Policy 28:99-115

von Hippel E (2005) Democratizing innovation. MIT Press, London

Tanner S (1999) How much do consumers spend? Comparing the FES and national accounts. In: Banks J, Johnson P (eds) How reliable is the family expenditure survey? Institute for Fiscal Studies, London

Witt U (2010) Product characteristics, innovations and the evolution of consumption. A behavioral approach, paper prepared for the conference on "Technical change: history, economics and policy" in honor of GN Tunzelmann, SPRU, March 2010

Witt U, Woersdorfer JS (2010) Parting with 'blue monday' - preferences and consumer responses to innovations. Papers on Economics and Evolution, Max Planck Institute of Economics, Jena, Nr 1110

Witt U (2001) Learning to consume - a theory of wants and the growth of demand. J Evol Econ 11:23-36 